\title{
Heritage site area type classification for Facility Management purposes
}

\author{
Author: András Bozány \\ Ph.D. student, Budapest University of Technology and Economics
}

HU ISSN 1418-7108: HEJ Manuscript no.: INF-060621-B

\begin{abstract}
Although heritage sites are various, Facility Management (FM) is maybe the most important process in the heritage site management systems. The similarities and differences of the corresponding sites should be considered before implementing common FM information systems that support more heritage sites with various area types. The presented classifications are collected and made primarily to support this process. Specialties of heritage sites were also observed from Facility Management point of view.
\end{abstract}

Keywords: Heritage, heritage site, heritage area, area type, classification, Facility Management

\section{Introduction}

The service level of Facility Management (FM) on heritage conservation sites and buildings has a significant disadvantage to that in the business area however the preserved cultural and natural values and the economical rationality would require greater efficiency and higher operational security level from the site management organizations.

In spite of that site management organizations nowadays merely do not use any supporting information systems to manage the preserved objects and facilities. The site management systems are almost never supported by Computer-Aided Site and Facility Management software, and unfortunately it is true even for the world heritage sites of UNESCO [1], and also for the heritage sites of the richest countries. The increasing number of heritage tourists and their enlarged expectations also require new solutions and more money spent on infrastructural investments. There are newly invented methods, considerations, hardware and software solutions that support the protection of the preserved values against theft, vandalism and catastrophes like fire or earthquake [2][3][4][5][6].

Trends show that activities and the changes with object movements on the sites are much faster now than twenty years ago.

For those sites and their corresponding maintenance organizations that are owned and financed primarily by the government, the budget usually has strict limits that do not allow such extra expenditures such as a new Facility Management system installation. Thereby the FM service level could not be improved significantly on these places during the last few decades however sometimes the operating costs could have been decreased with the application of the newly invented hardware, software and management solutions.

Facility Management is one of the core activities in almost every site management systems. If the heritage sites could be considered as facilities, they could be handled with well- customizable FM software.

There are several points where the heritage FM systems are special to the ordinary FM systems. The key properties will be analyzed and assessed from several point of views for both cultural and natural heritage FM systems.

The results of these classifications could be used for further developments of site management information systems.

There are on-site and centralized facility-related activities. Computer-Integrated Facility Management (CIFM) systems should be implemented to support the processes in only one site or to handle several 
sites at the same time. Centralized activities are usually performed in competence centers, far away from the managed site. In those information systems there are several further possibilities to make the system more cost effective.

The benefits of size-efficiency could be used in systems that support facility-dependent processes of several heritage sites because the FM activities on heritage sites are mostly similar thereby it is worth to implement common information systems to decrease the costs of Information Technology. Commonly used specialized site and/or FM information systems are advantageous if there is at least one centralized process.

Database queries in systems with shared database could be also used to create statistical reports that require information about more sites or to make comparisons among the sites based on various indicators.

\section{Background}

The need for modern FM supporting systems is rather high in the cultural and natural heritage management however the number of implemented CIFM information systems is not too high.

The issues of strategic facility planning are presented in [7] specifically for museums, but the resulting observations could be used for the most of the cultural heritage sites. It describes the elements of the museum-specific facility strategy. It also presents the aims, organization and the processes of strategic facility planning for museums.

Heritage sites might have some outer territories where agricultural activity is allowed, although with some limitations. Of course, these activities could be supported by the integrated heritage site management information system. The impact of farm management on the related information systems are analyzed with management and sociological methods in [8]. The value of Management Information Systems differs significantly between farms [9]. With some limitations it could be extended also for those outer areas belonging to heritage sites without agricultural activity.

\section{Approach, study methods}

There are several Facility Management information systems to handle more facilities that are owned by the same organization in the business sphere. Common heritage site management systems could be implemented to handle facilities of different heritage sites that are not owned necessarily by the same organization and are handled by one or more collaborating organizations.

The whole conservation area and its surrounding territories are owned by different people and organizations. There are several sites dominantly owned by common and/or non-profit organizations (like the local, regional or national government, church, etc.), while tourism facilities are often owned by firms and individuals. Fortunately, these sites are handled by authorities that can control even the actions of the owners.

Heritage sites are usually managed by the same governmental cultural or natural authorities. Common FM supporting information systems should be implemented for them.

However heritage sites are various, they have usually very similar FM related processes, with a plenty of centralized activities that could be supported by common FM systems well.

It seems that Facility Management (FM) is the most important process on most of the heritage sites and they are handled usually by governmental authorities and/or such organizations that can serve more sites permanently.

The similarities and differences of the corresponding sites should be considered during the implementation. However several groupings could be found that would be important for some FM issue, the following classifications are made primarily to support the system planning phase of these projects.

In this paper the focus will be mostly on the observation of different area types. Since these groupings were made mainly to support implementations of common CIFM-based site management systems, the information systems are also classified in this paper. Issues of the division of work in these systems are also discussed.

The heritage sites are observed by area related points of view: area and space types, zones, processes. Site information systems that manage Facility Management information are analyzed and classified by

- the primary goal of the information system, 
- the implemented data collection sub-processes

- their document management or by

- the support of (pipe, electric, etc.) networks in facilities.

\section{Analysis}

\subsection{Classification of heritage sites by heritage types}

Heritage sites are separated into three sub-areas: Based on [1] there are

- cultural and

- natural heritage sites and

- "mixed" sites belonging to both the cultural and natural heritage sites.

The main purpose of heritage site management is the conservation.

\subsection{Grouping places by facility planning point of view}

Classification of space types for strategic facility planning [7]:

Spaces for which the strategic facility planning team must be concerned are:

- Multifunctional or specialized space;

- Art and artifact display space;

- Storage of rare objects;

- Conservation and restoration;

- Gathering and educational space;

- Restaurant/museum shop;

- Administration/offices;

- Circulation;

- Physical plant.

\subsection{Site classification by fragmentation and the rate of built- in area}

The maintenance, improvements and the facility-related processes of buildings and not-built outer areas generally differ from each others. The distances in outer territories are dominantly larger than in buildings. Outer territories usually have longer distances than inner areas. The number and density of handled objects in buildings is often much higher than those for outer objects.

The built-in rate is not the only one that can determine how detailed status monitoring is needed. Among the buildings there are accentuated objects, and there might be even such buildings and objects that are not so important from Facility Management view, that it would need a more detailed structure. E.g. warehouses usually require significantly more detailed structure than such outbuildings where no handled facility- related objects are/can be held.

If we want to display every handled object on a map or map-like drawing in a FM application, we have to consider that there are rooms where important FM-related activities happen and/or handled objects can be found and there are also some rooms that are not so important.

FM application will show only the required objects on the screen. It also means that some furniture can be seen on the display while others are not visible.

In Facility Management supporting information systems the maximal expectation for the graphical interface is usually that the furniture and some objects should be showed in the building, while for other handled rooms with less importance the detailing is not so exactly done. 
Of course, Facility Management systems can manage objects with much less size than the most detailed available zoom. This time little objects are usually zoomed up or little pictures or signs show that there is an object.

Outer territories usually have much larger distances and areas so if little objects should be showed sometimes it would cause a serious problem.

Areas in a facility could be

- built-in areas with facility-related space,

- built-in areas with no facility-related space (out of FM),

- not built-in areas with facility-related space,

- not built-in areas with no facility-related space (out of FM).

The following types of area can be grouped if the do not consider the activities:

- one building,

- several buildings near to each others (e.g. with a common garden),

- several buildings far from each others (e.g. in different cities),

- building or buildings near to each others with the surrounding outer area,

- one or more outer area(s) without any building,

- several outer areas with buildings (at least one outer area with building is enough)

On the following list a classification of area types are presented for those cases when the FM activity is also important.

- one building with FM activity,

- several buildings with FM activity near to each others,

- several buildings with FM activity far from each others,

- several buildings with FM activity with surrounding FM active outer area,

- one or more FM active outer area(s) without any with FM active building,

- several FM active outer areas with FM active buildings (at least one outer area with building is enough)

- inactive facility areas: built or not built territories.

Sometimes the built-in areas can be handled like outer facilities while in other cases outer facilities are handled so detailed like built-in areas.

The areas should be classified by their FM activity level. There can be such systems where the FM information system is used only for the managing the most important sub-areas. In this case the areas with little FM activity level are usually handled with the old technology like e.g. ad-hoc methods, paper or with usual spreadsheet software tools.

Areas with low activity level are sometimes not handled in the FM supporting information system, this time their affairs are managed with ad-hoc methods using at most papers or independent spreadsheet applications with general purpose.

On outer areas there may be such buildings that are not detailed for displaying purposes in the FM information system. Outer areas like ruins of buildings might require so detailed maps for the FM application as if they were inner territories. 


\subsection{Human influence}

Outer areas can be also separated into sub-areas with and without human influence on heritage site management FM systems. For those without human affect the most typical examples are some untouched woods, jungle, deserts, etc. Gardens, parks, cultivation areas, pasture fields were affected by human.

Some original natural territories with unique values have become tourist targets lately so these places have not remained untouched in fact. In spite of it the aim of the Facility Management is to conserve their status as they were without human influence. In the FM system those areas belong to those territories where human influence should be kept on minimal level, e.g. only to avoid catastrophes.

If a Facility Management information system handles more than one site and/or other facilities, it might occur that the system is not customized well to handle some special properties for some sites. It is usual when with previously working (earlier customized) FM information systems also such new sites have to be managed that have such specialties that are not supported by the system. This time the model will not be implemented perfectly in the supporting information system thereby the remaining parts that would support the specialties are simply left away and handled with ad-hoc methods or managed outside the supporting information system.

If the facility includes different area (or sub-area) types, e.g. a museum building with a natural conservation area, special care should be given to avoid disproportion.

In the given case it is assumed that the objects of the museum have been collected perfectly while only a few objects of the conservation area have been registered until the begin of the FM information system implementation. This time it might happen that the system will handle all the objects in the museum while some very important objects in the surrounding conservation area will not be used. Such system implementations should be avoided to ensure a balanced, appropriate conservation level.

\subsection{Grouping the areas by application}

- Heritage conservation area without economic usage.

- Area in economic usage, with low or zero conservation activity.

- Mixed application: both economic and also under conservation. Sometimes conservation needs some animals, such as in case of pasture fields.

- Allocated areas to support conservation activities e.g. warehouses to store tools for catastrophes or offices and computer rooms on the area of the facility where the site management system is accessible and/or used).

Generally economic activities are done on most parts of the facility. Some of them support heritage conservation while others are independent from it. Sometimes even in the most strictly protected core facility territories have such places where economic activities are done without conservation purposes.

\subsection{Site zonation}

The limits of the planned on-site FM activity should be also determined at new site FM system implementations. This area is usually not the same like the protected territory.

Modern FM systems ([10], [11], [12], etc.) can show the objects on their current positions on the display for the users. The implementation requires one or more maps and floor-plans, but the limits of the handled area also should be determined.

The showed area is the facility area. Of course, the showed area can differ from either the limits of the protected area or any of the core, buffer and transition zones. It also does not mean that every FM-related activity is done inside this area but all the managed objects are usually inside the showed facility area.

\subsection{Zonation method for UNESCO heritage sites}

On UNESCO sites the conservation area is divided into delimited core and surrounding buffer zones and there is a transition zone.

Based on [13] sites like biosphere reserves are organized into three interrelated zones, known as the core area, the buffer zone and the transition area and only the core area requires legal protection. 


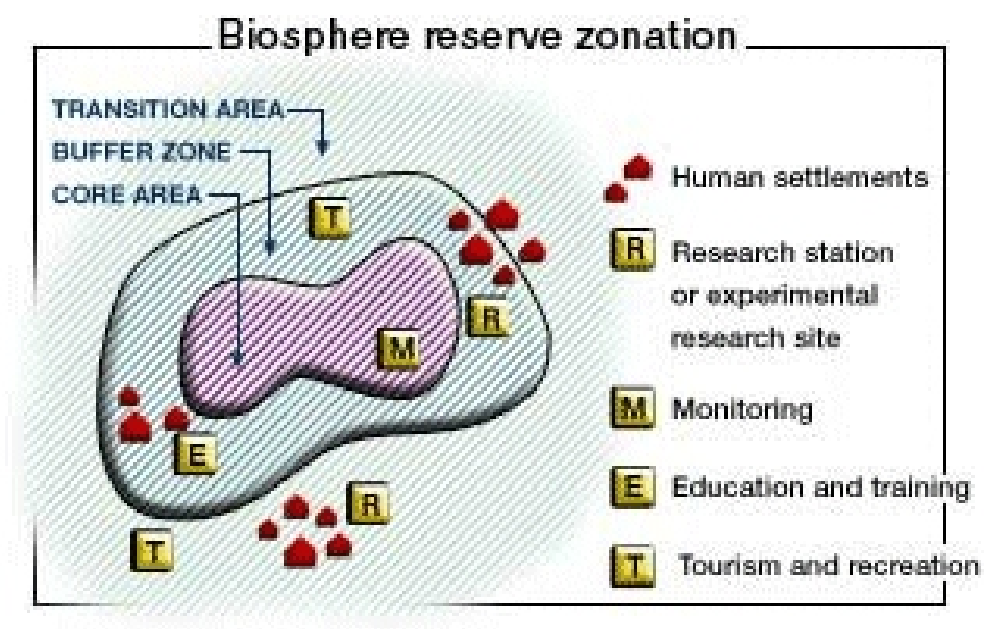

Figure 1: Biosphere reserve zonation (source: [13])

In other sources also the buffer and/or transition zones are called peripheral zones [14].

The strictly protected zone apparently corresponding with the "core zone" in MaB terminology [13]) and some maps also show areas of economic use or zone of anthropogenic landscapes (probably corresponding with the "transition zone") [15].

The conservation view of the 'buffer' is that of a peripheral zone where restrictions are placed on resource use or special development measures are taken to enhance the conservation value of the area [16]. Alternative definitions have emerged from others involved with buffer zones. Saharia [17] opts for "a type of multiple use area from where the people could be provided forest products and use". Brown [18] offers another definition embracing the human element as beneficiary: "An area inside or adjacent to a protected area where a harmonious relationship between the natural environment and people is promoted" [19].

The transition areas may include numerous small towns and villages with many tourist facilities. Different management regimes are required for each zone and each ecosystem type.

The core area needs to be legally established and give long- term protection to the landscapes, ecosystems and species it contains. It should be sufficiently large to meet these conservation objectives. As nature is rarely uniform and as historical land-use constraints exist in many parts of the world, there may be several core areas in a single biosphere reserve to ensure a representative coverage of the mosaic of ecological systems. Normally, the core area is not subject to human activity, except research and monitoring and, as the case may be, to traditional extractive uses by local communities.

A buffer zone (or zones) which is clearly delineated and which surrounds or is contiguous to the core area. Activities are organized here so that they do not hinder the conservation objectives of the core area but rather help to protect it, hence the idea of "buffering". It can be an area for experimental research, for example to discover ways to manage natural vegetation, croplands, forests, fisheries, to enhance high quality production while conserving natural processes and biodiversity, including soil resources, to the maximum extent possible. In a similar manner, experiments can be carried out in the buffer zone to explore how to rehabilitate degraded areas. It may accommodate education, training, tourism and recreation facilities. In buffer zones, emphasis is on sustainable use of the natural resources for the benefit of local communities.

An outer transition area, or area of co-operation extending outwards, which may contain a variety of agricultural activities, human settlements and other uses. It is here that the local communities, conservation agencies, scientists, civil associations, cultural groups, private enterprises and other stakeholders must agree to work together to manage and sustainably develop the area's resources for the benefit of the people who live there. Given the role that biosphere reserves should play in promoting the sustainable management of the natural resources of the region in which they lie, the transition area is of great economic and social significance for regional development [13].

These outer areas could belong to various types: other territories of the city/cities or other cultivated agricultural areas. 


\subsection{Zones and conservation-independent areas}

FM solutions for heritage site management purposes can be implemented to support facility-dependent processes on either the core, the buffer or the transition zones and on some outer areas, too.

It is clear that the core area includes the most valuable objects while the buffer and transition areas have less importance.

It means that when Facility Management systems will be computerized, they should choose from the following possibilities:

- Only the core area (either more areas in the same time)

- The core and buffer zones

- The core, buffer zones and some transition areas and their objects and activities are supported. Other facility areas could be supported as well.

The first solution provides the minimum protection level and the cheapest to implement. It is not the suggested solution without implementing the buffer zone.

The surrounding buffer zones are mostly also involved in the FM system. It can ensure the expected long-term security for the objects in the conservation area.

Sometimes other facility areas and further surrounding areas like transition zone or its parts are also involved in the FM system. These are the most expensive systems with the biggest database.

It is also possible to change the limits of the implemented zones later, perhaps in a new project.

There are some systems that are/were implemented another way. E.g. in the most site system models earlier existed only protected and not protected areas.

However the rule is that the core, buffer and further zones should be delimited without using the old limits of the protected zone, it can be stated that usually the limits of the earlier protected area(s) will be inside the borders of the buffer zone(s). Furthermore the limits of the earlier protected area(s) usually will be the new borders of the core zone(s) and the surrounding buffer zone(s) should be delimited [20].

If we use earlier methods, and there are only protected and not protected areas, the FM system should manage at least the whole protected area, of course, but some another areas could be supported as well.

\section{Area classification by size and the spread of its parts}

This classification separates sites into four groups:

- Sites with one point-like area,

- Sites with one larger area,

- Sites with more areas in a limited region,

- Networks.

The applied method assumes that every site consists of well limited areas. There are significant characteristic differences among these groups from the view of the site Facility Management, too.

\subsection{Point-like areas}

A sub-grouping could be performed to distinguish between built and non-built point-like sites. Built sites are typically cultural heritage sites while natural heritage sites usually belong to the next main groups (with some exceptions).

- Built sites with point-like areas include only one building of any size (e.g. with any rooms). For the installation of Facility Management systems it means that only one building should be handled and modeled including stages, rooms, men, agreements, objects, etc.

Each site with one building belongs to this sub-group. There are several cultural heritage sites with point-like areas like most of the museums and castles. Natural sites usually belong to the next sub-group however there are also natural sites surrounded with built objects that belong to this group (like e.g. medicate springs with thermal baths and hotels). 
- Non-built point-like sites have small outer areas. From the view of FM it is similar to the modeling of a building without ordinary walls. Squares, ruins of a former building or point-like natural sites with small base areas without building belong to this sub-group (e.g. waterfalls, springs, peaks and their close surrounding areas).

\subsection{Sites with one larger area}

These sites consist of only one larger area (that is typically larger than a building). They always include outer areas but of course, they can include built objects, too.

Non-built outer sites are mostly natural heritage sites. Built larger areas usually mean cultural heritage sites. The cities are typical examples of large cultural areas.

\subsection{Sites with more areas in a limited region}

This group consists of sites with more separated territories in a limited region. Most of the natural parks with more separated sub-territories belong to this group. More point- like and/or larger areas can be handled together this way. Networks and separated areas with a limited region could be distinguished because these sites have sub-areas from a smaller region, near to each others. Networks consist of much more sub-areas, and the range would be as large as some country.

\subsection{Networks}

Site networks consist of large number of sub-areas that are connected thematically together. The region where the network elements are spread is sometimes larger than the size of a country.

Point-like and larger areas could be also organized into networks thematically. Typical examples are the museum- and rural house networks or thematically connected networks of natural conservation areas.

From Facility Management point of view these sub-areas have the same similarities, thus modeling and handling of these sites together can be more cost-efficient.

\subsection{Special heritage sites}

The underwater and underground sites represent two specific groups that have different characteristic like the most of the sites. These sites could be also grouped: there are smaller, point-like sites like wracks, and even caves with larger areas.

The required methods to model these areas for FM purposes are usually similar to those of the ordinary outer areas, but sometimes multi-staging is also required (e.g. for mines and caves with more stages).

\section{Site classification by used facility-related functions}

The following categories should be distinguished by the supported actions:

- The FM activity is not done or cannot be done on the site (e.g. not handled sites).

- The FM function exists on the site but it is not registered (not planned ad-hoc method).

- The FM activity is implemented without a supporting information system thus the activities are registered on paper or using spreadsheet applications.

- The FM function is well supported with an information system.

- Some FM activities could be totally automated or can be supported with independent automatic processes so no human influence is needed. 


\section{Common vs. individual information systems for more}

organizations

It is important to decide which theoretically available FM functions would be meaningless or useless to be used (either without a supporting FM system), and which processes worth to be supported by the information system.

If more organizations do the FM tasks together, it requires a more complicated structure from the information system.

E.g. the information system is handled by a national organization but the local tasks are performed on the site by another branch of that organization or a different firm. From this point of view a different branch is equivalent to a different firm. The following list will explain the possibilities only for different organizations.

It is possible to perform the Facility Management by

- only one FM organization

- several FM organizations with separated responsibilities

- by processes,

- by areas,

- by time (e.g. different access rights to handle catastrophic situations),

- mix from the above,

- etc.

More FM organizations with not separated responsibilities are not suggested because there could be duplications, and no real responsible man in heavy situations.

Facility Management tasks could be done by one or more organizations. E.g. usually central governmental organizations provide a part of the facility-related tasks. The facility-related labor is usually divided among the central, local (city level) and on-site organizations. Central organizations can be either authorities of country, regional or world level.

If an object with unique values gets damaged it means that it cannot be restored or replaced so the whole mankind will lose something with priceless value. The contracts and agreements with other organizations or people about the usage of some conservation areas should include the special requirements of the territory application. The contracting policy also should ensure that the expected security level will be achieved in long-term with acceptable low risks on the conservation area and its surrounding territories. These activities could be either continuously, periodically, seasonally, occasionally done activities. E.g. by the selection on tenders the winner should not be the cheapest quotation if it cannot sustain that the conservable values will not be damaged or lost during its activity.

If the owner would like to manage his renters or would like to monitor even their activities in the facility, it means that much more information should be supported by the information system compared to that if all the FM-related activities are done by the same organization. In those cases computer integrated FM systems should be used to support the information management, mostly if in some areas the data change frequency is rather fast and the facility requires the handling of many information.

If there are a lot of renters, owners or other third party organizations (like cleansing companies) that are making some activities on the area, it also means that a lot of information should be handled on the area so it is usually worth to be supported by computerized FM systems.

There are other areas where the facility is divided among the owners. It is usual in the Facility Management because e.g. in office buildings it is often that there are rooms owned by different firms and people. For conservation areas it is also characteristic e.g. in old cities each house could be owned by different person.

But there is a difference: in conservation areas the requirements of the Facility Management are determined by only one main authority (usually this organization owns the FM system), while in nonconservation purposes the requirements for the applied FM systems and the facility strategy are mostly influenced by the owners, not outer authorizations or law.

If more organizations can access a commonly used site management system, the authorization rules have to be set up to control the database modification and access rights to some information among the organizations. 


\section{Grouping site information systems by their primary objective}

It is an issue if the purpose of the supporting information system is exactly to serve the conservation activities or not. There might be also such information systems that were implemented not primarily for heritage conservation purposes so several specialties will not be supported by the system.

E.g. the focus of the Facility Management nowadays is mainly on the built facilities, but for heritage site purposes (mostly for natural heritage sites) it is also important to manage outer areas that are not well supportable with every FM solutions.

It is possible that the same information systems are used commonly for FM purposes by more facilities but some of these facilities do not belong to conservation areas. The FM system was implemented to support bigger facilities that include the conservation area or some of its parts, too. This time the special requirements of the heritage places are not always can be fulfilled.

There are FM systems that support the management of the heritage sites where

- the primary objective is to serve the conservation area

- the primary requirements were not collected primarily for conservation purposes, just simple FM purposes:

- where the conservation-related special additional requirements are supported

- where the special requirements are not supported by the information system. If that information system cannot be changed, the special requirements should be supported another way like via system integration.

\section{$9 \quad$ FM systems and functions groups by the computer integration level}

- Not computerized FM system or not supportable process.

- Low-level computer support: only for general-purpose spreadsheet or document management applications

- High-level computer support: FM support with FM information system, depending on which functions are supported with computer applications (and also with hardware solutions)

The list above can be applied either to the whole FM system or for each possible FM functions one by one.

Of course, all of these possibilities should be analyzed for each FM function areas or either even generally for the FM activity.

The International Facility Management Association (IFMA) has grouped the facility-dependent responsibilities into several major functional areas [21]:

- long-range and annual facility planning,

- facility financial forecasting,

- real estate acquisition and/or disposal,

- work specifications, installation and space management,

- architectural and engineering planning and design,

- new construction and/or renovation,

- maintenance and operations management,

- telecommunications integration, security and general administrative services.

Based on Kast, F. and Rosenzweig, J. [22] the following FM processes should be distinguished: 
- Status documentation

- Area Management

- Facility-related Human Resource Management

- Inventory

- Cleansing

- Key/Access/Security

- Moving

- Network Management (telecommunication, electric data processing, lighting)

- Fire-protection

- Contract Management/Occupant Management

- Property Management/Property Portfolio Management

- Technical Work Management in Buildings

- Machines, Equipments

- Building Lighting

- Maintenance/Repairs

- Service-Desk (Helpdesk)/Catastrophe Management

- Place and Building Cost Calculation.

\section{Categorization by FM dependent data collection}

The information collection is one of the key operational processes in every FM systems.

Efficient reactions with fast reaction times could be achieved only if the input information is collected regularly, exactly in the scheduled sampling times, and the collected information is correct and dependable. Since the decision making is based on the input information, it is elementary that all these information will be really collected in time.

If the facility-dependent costs should be cut for some reason, the simplest solution is usually to reduce the pattern-sampling frequency, because it causes fewer problems than the wage cutting would do. Radical cuttings lead to unpredictable results, because it is not sure any more that the catastrophes will be recognized in time. In other cases the possibilities of cost-effective prevention will be lost, so in long-term this way will be more expensive.

It is usual expectation that the facility-dependent costs should be less with FM would be without such a system. However, by the start of the FM system it usually turns out that the current facilitydependent data collection is not enough frequently done for effective prevention. The problem is that this time everybody wants to reach a better service level and cost-reducing at the same time, and it is mostly not possible. If it turns out that the protection level could be increased, usually it becomes the most dominant goal in the system therefore at last the costs of the system will be larger than before. Moreover, the installation of the desired FM technologies might require costly investments.

The costs of reactions are usually much higher than the prevention would be. For the protected objects it is suggested to apply more preventive methods than in the business sphere, because the these damages cannot be fixed simply, by replacing. Of course, some effects such as the corrosion cannot be blocked perfectly.

It is among the most important purposes of the modern FM to find out in an early time what to do to prevent problems (possibly with higher costs). In those systems where the collected information is available, the Facility Management some extra expenditures could be avoided.

If the input information is not collected and evaluated in time, it does not matter if there is any expensive monitoring information system, because it cannot support good decisions. 


\section{FM-related document management}

The facility-dependent document management can be done by

- outer document management software applications or

- FM software that can support document management processes or

- using document management software that are integrated with an FM solution or

- the required information could be written/stored on paper or

- using spreadsheet software or

- without tools, only in mind (the last three solutions mean ad- hoc decisions).

Such documents are among more

- contracts and agreements to do some FM tasks or for rental and owners,

- task and process descriptions,

- papers of owners,

- work documents,

- etc.

\section{Network infrastructure management support in FM systems}

Network infrastructures require different handling than the area-based approach. Larger FM systems offer the possibility to handle different types of networks in the same system. The most recently used networks are the electric, phone, computer network and other cables, different pipelines like water, sewage-water, gas, etc., and there are some networks in the security and monitoring systems like e.g. the networked parts of fire protection systems.

With the permanent development of the infrastructural solutions the more systems are built in the facilities, therefore networks in facilities represent the more percent inside the total value of the facilities.

Some FM supporting information systems are not able to manage networked facilities, because the organization needs FM supporting only for Area-Management purposes.

\section{Conclusion}

On most of the heritage sites maybe the Facility Management is the most important management process. These cultural and natural sites are handled usually by governmental authorities and/or such organizations that can serve more sites permanently. Though sometimes the government is not the only owner on the whole territory, the dangerous actions of owners should be blocked by authorities, law and several agreements.

Cultural and natural authorities can use common management information systems for more sites that can support the Facility Management, too.

Before implementation of such site information systems heritage sites should be analyzed from many points of view. It is possible to manage various types of sites in the same system, even together cultural and natural heritage sites on different places. This process is expected to be done in many countries. Heritage sites are classified in this paper from area-based point of view. Issues of the work division between the central and local organizations are also discussed.

However these classifications are made primarily to support common FM system implementations, its results could be used for other study and information system customization purposes, too.

Acknowledgements

The author would like to acknowledge the valuable help we received from Ferenc Kiss Ph.D. and Dr. Lia Bassa from the Budapest University of Technology and Economics Department of Information and Knowledge Management. 


\section{References}

[1] http://www.unesco.org, 2005

[2] Véronique Dauge: Post-war Recovery in Cambodia, Museum Management and Curatorship, Vol. 16, No. 2, pp. 164-172, 1997

[3] Brent W. Ritchie: Chaos, crises and disasters: a strategic approach to crisis management in the tourism industry, Tourism Management 25 (2004) 669-683

[4] C. Gavarini / Soil Dynamics and Earthquake Engineering 21 (2001) 460 459-466

[5] M. Sebastian, V. Jayaraman, M.G. Chandrase: Facilities Management using remote sensing data in a GIS environment, Acta Astronautica Vol. 43, No. 9-10, pp. 487-491, 1998

[6] Editorial: Castastrophy Management, Museum Management and Curatorship, Vol. 19, No. 2, pp. 115-120, 2001

[7] Kathy O. Roper, Jeffrey L. Beard: Strategic facility planning for museums, Museum Management and Curatorship 20 (2005) 57-68

[8] J.A.A.M. Verstegen, R.B.M. Huirne: The impact of farm management on value of management information systems, Computers and Electronics in Agriculture, 30 (2001) 51-69

[9] Verstegen, J.A.A.M., Dijkhuizen, A.A., Huirne, R.B.M., King, R.P., 1995. Quantifying economic benefits of sow-hed management information systems using panel data. Am. J. Agric. Econ. 77, 387-396.

[10] Graphisoft Rt, http://www.graphisoft.com, 2005.

[11] Nemetschek AG, http://www.nemetschek.de, 2005.

[12] Speedikon AG, http://www.speedikon.de, 2002.

[13] Frequently asked questions on biosphere reserves, 2005, http://www.unesco.org/mab/nutshell.htm

[14] The Cévennes National Park, http://www.bsi.fr/pnc/English/body_english.htm, 2005

[15] Jan Kvet, MaB Bureau, \& Tobias Salathé, Ramsar Secretariat: Ramsar Advisory Mission No. 53: Ukraine (2003), http://www.ramsar.org/ram/ram_rpt_53e.htm

[16] Sayer, 1991 in John B Hall \& WA Rodgers: Buffers at the boundary; Rural development forestry network; Network paper 13a, Summer 1992, ISSN 0968-2627 (formerly Social Forestry Network ISSN 0951-1857).

[17] Saharia (1983) in John B Hall \& WA Rodgers: Buffers at the boundary; Rural development forestry network; Network paper 13a, Summer 1992, ISSN 0968-2627 (formerly Social Forestry Network ISSN 0951-1857)

[18] Brown (1992) in John B Hall \& WA Rodgers: Buffers at the boundary; Rural development forestry network; Network paper 13a, Summer 1992, ISSN 0968-2627 (formerly Social Forestry Network ISSN 0951-1857)

[19] John B Hall \& WA Rodgers: Buffers at the boundary; Rural development forestry network; Network paper 13a, Summer 1992, ISSN 0968-2627 (formerly Social Forestry Network ISSN 0951- 1857)

[20] Jan Kvet, MaB Bureau, \& Tobias Salathé, Ramsar Secretariat: Ramsar Advisory Mission No. 53: Ukraine (2003), http://www.ramsar.org/ram/ram_rpt_53e.htm

[21] IFMA, http://www.ifma.org, International Facilities Management Association (IFMA), 2002

[22] Kast, F. and Rosenzweig, J. (1985) Organization and Management: A Systems and Contigency Approach. McGraph-Hill, New York 